\title{
Rancangan Aplikasi Kasir Berbasis Dekstop Pada Toko Citra MJ Cikarang
}

\author{
Diah Wijayati ${ }^{1, *}$, Sunarto Ade Irawan ${ }^{1}$, Eko Haryadi ${ }^{1}$, Yuli Komalasari ${ }^{2}$, Dede Mustomi ${ }^{3}$ \\ 1 Sistem Informasi; Universitas Bina Sarana Informatika; Jl. Raya Cibarusah No. 168 Cikarang \\ Square, Cikarang Selatan, Bekasi, Jawa Barat, 17550, Telp. 021-89845468, Fax. 021- \\ 89845467, e-mail: diah.dhw@bsi.ac.id, adeirawan.ai100@gmail.com, eko.ehy@bsi.ac.id \\ 2 Teknik Informatika; Universitas Bina Sarana Informatika; Jl. Kramat Raya No.18, Ringroad \\ Barat, Cengkareng, Jakarta Barat, 11710, email: yuli.yks@bsi.ac.id \\ ${ }^{3}$ Administrasi Bisnis; Universitas Bina Sarana Informatika; Jl. Kramat Raya No.98, Senen \\ Jakarta Pusat, 10450, Telp.021-21236158 Ext.704, email: dede.ddo@bsi.ac.id \\ * Korespondensi: e-mail: diah.dhw@bsi.ac.id
}

Diterima: 17 September 2021; Review: 25 Oktober 2021; Disetujui: 27 Oktober 2021

Cara sitasi: Wijayanti D, Irawan SA, Haryadi E, Komalasari Y, Mustomi D. 2021. Rancangan Aplikasi Kasir Berbasis Dekstop Pada Toko Citra MJ Cikarang. Bina Insani ICT Journal. Vol.8 (2): 136-145.

\begin{abstract}
Abstrak: Citra MJ merupakan perusahaan yang mempunyai suatu usaha penjualan berupa pakaian. Dimana Citra MJ dalam proses usahanya masih terkendala dalam hal pengelolaan data. Selain itu sistem pembayaran transaksi yang dilakukan oleh kasir masih bersifat manual sehingga menyebabkan banyak waktu yang terbuang. Sistem yang masih manual dalam pengelolaan data menyebabkan kasir kesulitan dan membutuhkan waktu yang lama dalam mencari data produk, data pelanggan maupun data transaksi. Karena itu untuk mempermudah hal tersebut toko Citra MJ membuat pengolahan data dan pembuatan laporan administrasi sistem kasir, Toko Citra MJ memanfaatkan penggunaan teknologi salah satunya penggunaan teknologi komputer dengan membuat perancangan aplikasi program kasir untuk toko Citra MJ. Tujuan dari perancangan program ini adalah membantu kegiatan kasir dalam hal pengolahan data seperti pengolahan data produk, data pegawai, data transaksi, data pelanggan serta pembuatan laporan di toko MJ. Aplikasi program ini sementara ini di peruntukkan untuk kasir saja ke depannya tidak menutup kemungkinan mengembangkan menjadi aplikasi yang berbasis web. Sistem kasir ini menggunakan metode waterfall, yang mana metode ini dilakukan secara berurut mulai dari analisa, rancangan, pengkodean, pengujian sampai implementasi. Dalam perancangan program kasir di toko MJ bahasa pemrograman yang digunakan adalah java, database xampp dengan software pendukung adalah NetBeans IDE 8.1. Dengan melihat dari hasil pengujian yang menggunakan metode kuisioner diperoleh tngkat kepuasaan pengguna aplikasi program kasir sebesar $82,12 \%$, hal ini berarti bahwa pengguna sangat puas dengan aplikasi program kasir.
\end{abstract}

Kata kunci: program kasir, rancangan program

Abstract: Citra MJ is a company that has a sales business in the form of clothing. Where Citra $\mathrm{Mj}$ in its business process is still constrained in terms of data management. In addition, the payment system for transactions carried out by the cashier is still manual, causing a lot of wasted time. The system that is still manual in data management causes cashiers to have difficulty and takes a long time in finding product data, customer data and transaction data. Therefore, to make this easier, the Citra Mj store makes data processing and makes administrative reports for the cashier system, the Citra Mj store utilizes One of the uses of technology is the use of computer technology by designing a cashier program application for the 
Citra MJ store. The purpose of this program design is to assist cashier activities in terms of data processing such as product data processing, employee data, transaction data, customer data and report generation. This program application is currently intended for cashiers only, in the future it is possible to develop it into a web-based application. This cashier system uses the waterfall method, where this method is carried out sequentially starting from analysis, design, coding, testing to implementation. In designing the cashier program at the Mj store the programming language used is java, the xampp database with supporting software is NetBeans IDE 8.1. By looking at the test results using the questionnaire method, the level of user satisfaction of the cashier program application is $82.12 \%$, this means that the user is very satisfied with the cashier program application.

\section{Keywords: cashier program, program design}

\section{Pendahuluan}

Dalam dunia usaha untuk mempertahankan dan mengembangkan usaha bisnis perlu adanya informasi yang akurat dan tepat waktu, semua itu untuk membantu pembisnis dalam pengambilan keputusan dan langkah yang penting untuk kemajuan usahanya. Karena itu dibutuhkan suatu pengolahan data yang handal dan akurat, salah satunya rancangan aplikasi program desktop.

Rancangan program aplikasi berbasis desktop adalah rancangan aplikasi yang dapat dijalankan secara offline atau tanpa jaringan intenet, rancangan aplikasi desktop sendiri mempunyai manfaat untuk memberikan kemudahan bagi pengguna komputer atau laptop dalam mengelola data sehingga hasil dari rancangan aplikasi tersebut dapat membantu kasir dalam membuat laporan yang tertata rapi, tepat waktu dan dapat di pertangung jawabkan

Dalam wulandari [1] dapat dikatakan bahwa "penjualan adalah suatau kegiatan yang dilakukan oleh penjual di mana penjual akan menjual barangnya atau jasa dengan harapan akan memperoleh keuntungan dari transaksi-transaksi yang terjadi". Selain itu penjualan dapat juga diartikan sebagai "pemindahan atau pengalihan terhadap hak atas kepemilikan barang atau jasa dari pihak penjual ke pembeli". Citra MJ merupakan sebuah toko garmen yang menjual bermacam-macam pakaian seperti pakaian anak-anak, remaja, dan dewasa. Kegiatan penjualan pada Citra MJ masih menggunakan sistem kasir yang cukup sederhana yaitu hanya dengan di catat pada sebuah buku pelayanan yang nanti bisa saja catatan tersebut hilang atau terselip, sehingga pelayanan kepada pelanggan menjadi kurang maksimal, selain itu juga pada toko Citra MJ perhitungan hasil transaksi hanya mengandalkan sebuah kalkulator yang mana kesalahan bisa timbul karena kelalaian dari kasir, walaupun dalam perhitungan transaksi telah didukung dengan sebuah kalkulator akan tetapi tetap saja dalam transaksi masih bisa memiliki kelemahan dalam proses perhitungan dan tidak jarang pula terjadi kesalahan dalam faktor perhitungan dikarenakan kesalahan tersebut bisa karena pembacaan kode barang atau harga barang, disamping itu tidak adanya pendataan stok barang pada Citra MJ menjadi masalah yang cukup serius sehingga tidak jarang disaat barang sudah habis tidak diketahui oleh pemilik. Citra MJ mengharapkan sebuah program yang mendukung bisnisnya, mulai dari sistem yang memudahkan pemilik atau karyawan dalam melakukan pengolahan data menjadi lebih efisien dan efektif, serta membantu pelayanan kasir agar menjadi lebih efektif dalam melayani pelanggan.

Sistem perancangan program desktop ini masih sangat sederhana karena tujuan awal dari pembuatan aplikasi program ini adalah membantu kinerja kasir yang masih manual ke komputerisasi dengan sebuah aplikasi program kasir. Rancangan program yang dibuat diperuntukkan bagi kasir toko $\mathrm{Mj}$ agar dapat membantu kerja kasir yang tadinya lambat menjadi lebih cepat, akurat dan tepat Ke depannya dengan melihat perkembangan toko tidak menutup kemungkinan untuk membuat rancangan bangun yang berbasis web untuk meningkatkan penjualan serta keuntungan yang besar pada toko $\mathrm{MJ}$, selain itu juga dapat memudahkan pelanggan dalam berbelanja di toko MJ. Dalam hal ini metode yang digunakan dalam pembuatan aplikasi program kasir ini adalah model waterfall[2] yang dimulai dari "Requiment analysis, system desain, Implementation, Intrigration \& Testing, Operation and Maintenance." Konsep model waterfall biasanya merupakan pendekatan yang dikendalikan oleh dokumen. Waterfall sendiri merupakan model yang membangun perangkat lunak atas dasar Daur Hidup Perangkat Lunak (SDLC), SDLC sendiri merupakan model yang mempunyai beberapa struktur diantaranya adalah perencanaan, analisis, design dan implementasi. Menurut kadir dalam 
Yuliandari [3] definisi bahasa pemgrograman adalah "suatu untaian kata-kata yang berupa instruksi ataupun perintah-perintah yang biasanya terdiri dari banyaknya baris yang hanya bisa dimengerti oleh komputer". Rancangan menurut Winarti dalam Febriyanto [4] "Rancangan adalah proses menganalisa kebutuhan dan mendeksripsikan dengan detail komponenkomponen yang akan diimplementasikan", juga dijelaskan pengertian dari "Bangun yaitu menciptakan suatu sistem baru atau memperbaiki sistem yang sudah ada". Sedangkan pengertian "Program adalah merupakan suatu himpunan atau kumpulan-kumpulan intruksi tertulis." Yang mana orang yang membuat suatu program sering disebut pemrograman atau bias disebut juga programmer.menurut Kawegian [5]. Dalam Kadir [6] Siklus pengembangan program dalam menyelesaikan masalah yang hendak dituangkan dalam program, terdapat empat langkah yang umum dilakukan adalah sebagai berikut analisa masalah, Perancangan program, pembuatan program dan pengujian program.

\section{Metode Penelitian}

Perancangan aplikasi program kasir menggunakan metode waterfall yang meliputi analisa kebuthan, desain sistem, pengkodean, pengujian program, penerapan program dan perawatan program. Dalam hal ini akan di bahas mengenai perancangan program, pengkodean, proses program, perancangan basis data dan pengujian sistem. Perancangan aplikasi program kasir MJ ini dibangun menggunakan bahasa pemograman java NetBeans dengan database MySQL. Adapun program ini terdiri dari tiga level yaitu kasir, pemilik dan pramuniaga yang dimulai dari input data pegawai, data produk, data transaksi sampai cetak laporan disamping itu program ini hanya digunakan untuk lingkungan dalam toko MJ saja, yang berarti hanya karyawan dan pemilik yang memiliki akses terhadap program ini. Dalam pengembangan perangkat lunak aplikasi program kasir menggunakan metode waterfall, Menurut Yurindra [2] Di dalam metode waterfall terdapat beberapa tahapan diantaranya 1) Reqruitment Analysis dimana pada tahap ini peneliti mengamati setiap masalah yang terjadi di Citra MJ khususnya pada sistem kasir, selanjutnya setelah dilakukan analisis tahap berikutnya mendefinisikan masalah terjadi sehingga dapat memberikan rekomendasi untuk perbaikan, software yang di usulkan dalam perancangan program kasir ini adalah script java netbeans dan database yang digunakan dalam aplikasi program ini adalah database MySQL. 2) Tahapan berikutnya mendesain sistem, pada tahap ini dilakukan pembangunan terhadap perangkat lunak, peralatan pendukungnya meliputi desain sistem dengan menggunakan Entity Relational Diagram (ERD), Logical Record Structure (LRS), untuk rancangan program menggunakan diagram Alir Program (Flowchart) dan HIPO (Hierarky Input Proses Output) yaitu membuat rancangan input output serta membuat rancangan keamanan program. 3) Selanjutnya pemeliharaan atau implementation pada tahap ini dijelaskan semua perintah-perintah dari listing program atau coding yang digunakan untuk proses pengolahan data pada saat pembuatan aplikasi program kasir pada toko Citra MJ. 4) Tahap berikutnya Integration \& Testing pada tahap ini dilakukan pengujian terhadap aplikasi program sepert black box testing, 5) pada tahap terakhir yaitu Operation \& Maintenance yang mana pada tahap ini perlu adanya program lain yang dapat mendukung program kasir ini, dan pemeliharaan dari aplikasi program kasir tersebut.

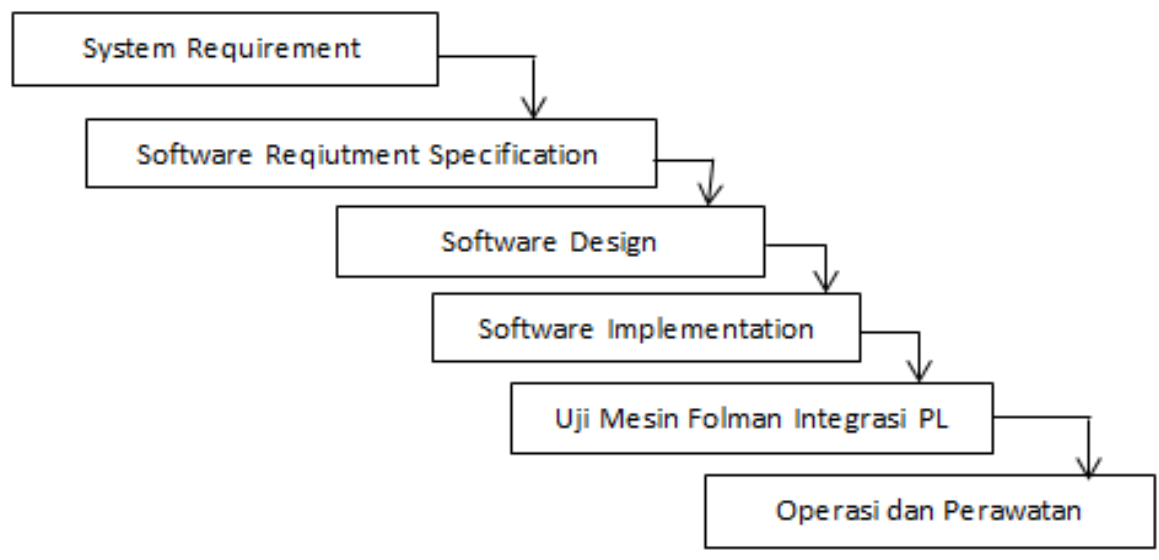

Sumber: Yurindra (2019)

Gambar. 1. Konsep Sederhana Waterfall 
Gambar 1 menjelaskan tentang konsep sederhana dari pengembangan perangkat lunak, yaitu model waterfall yang terdiri dari requirement sistem, spesifikasi software requirement, sistem desain, implematation, integration dan testing terakhir operation dan maintenance.

Menurut Haqi [7] salah satu software pendukung dalam aplikasi program kasir ini adalah NetBeans, definisi dari NetBeans itu sendiri adalah "Salah satu perangkat lunak yang akan digunakan untuk membangun perangkat lunak yang lain". Aplikasi yang dapat digunakan untuk membangun suatu perangkat lunak terseobut adalah aplikasi yang berbasis java Standart Edition, Java Enterprise Edition, Phyton dan lain-lain. Sedang bahasa pemograman yang digunakan adalah Java, dimana java merupakan bahasa pemrograman yang sangat terkenal dan dapat membantu untuk menulis atau membuat suatu program, sedangkan Java sendiri bersifat Write Once, Run Anywhere (program yang hanya ditulis satu kali dan bisa berjalan pada banyak platform). Hal ini tidak aneh karena java sendiri merupakan aplikasi yang bisa ditemukan di lingkungan komputer maupun smartphone tanpa perbedaan yang berarti.

Menurut Rusmawan [8] "Basis data atau database dapat dipahami sebagai suatu kumpulan file-file data yang berrelasi dan disimpan secara bersama-sama pada suatu media penyimpanan, agar tidak terjadi penggadaan data atau data yang dobel, "selain itu juga data dapat disimpan dengan cara-cara tertentu agar mudah untuk digunakan ketika akan ditampilkan kembali. Dalam suatu basis data ada juga data yang dapat digunakan satu atau lebih untuk program-program aplikasi secara optimal, data yang tersimpan tidak mengalami bergantung dengan program yang akan menggunakannya". Data yang tersimpan tidak mengalami kerangkapan data, sehingga proses nya dapat berjalan dengan mudah dan terkontrol, proses itu sendiri seperti proses aritmatika dan modfikasi data. ERD (Entity Relational Diagram) adalah "salah satu teknik diagram yang bisa membuat suatu model untuk keperluan data dalam suatu organisasi yang dilakukan oleh suatu sistem analis dengan alur persyaratan analisis dan proyek pengembangan sistem". Desain dan pembangunan program berfokus dalam bagaimana cara membuat sistem dalam pemenuhan keperluan dalam tahap analisis" [9]. Menurut Simarmata dalam Fridayantie [10] Logical Record Structure (LRS) adalah "Suatu proses dimana struktur record-record pada tabel yang terbentuk dari hasil relasi antar himpunan entitas, yang mana dapat menentukan kardinalitas, jumlah tabel dan macam kunci salah satunya kunci tamu atau ForeignKey (FK)". Yogiyanto dalam Pradiningtyas [11] mendefinisikan struktur kode atau pengkodean adalah "Suatu kumpulan digit (angka), huruf, dan karakter-karakter khusus yang dapat dirancang dalam bentuk suatu kode." Dimana fungsi kode itu sendiri adalah untuk mengkelompokkan data, menambah data kedalam komputer, Selain itu pengkodean digunakan juga untuk memberikan berbagai macam informasi yang berhubungan dengan kode tersebut. Sarosa [12] mendefinisikan symbol flowchart adalah untuk menggambarkan urutan suatu proses yang dimulai dari simbol mulai sampai end, di dalamnya termasuk proses pengolahan data. Flowchart juga dapat digunakan untuk menjelaskan suatu program dengan menggambarkan algoritma dari suatu aplikasi yang terdiri dari urutan proses, prosedur maupun aliran kerja. Pengujian program salah satunya adalah black box testing. Menurut Rosa dalam Wijayanti [13]. Definisi dari pengujian black-box adalah pengujian software jika dilihat dari sisi persyaratan secara fungsi tanpa melakukan pengujian perancangan dan coding, ini merupalkan tahap akhir pengujian program.

\section{Hasil dan Pembahasan Analisa Kebutuhan}

Langkah awal untuk menentukkan gambaran perangkat lunak dalam pengembangan pembuatan suatu proyek salah satunya adalah analisa kebutuhan. Dalam aplikasi program kasir ini terdiri dari analisa kebutuhan pemilik yang mencakup pemilik dapat mengolah data barang toko $\mathrm{Mj}$, data pegawai, data pelanggan, data penjualan dan data laporan dengan edit, hapus dan tambah, analisa kebutuhan kasir yang mencakup kasir dapat mengolah data barang, data penjualan dan laporan dan analisa kebutuhan pramuniaga yang mencakup pramuniaga dapat melihat daya barang dan dapat mengolah penjualan.

\section{Entity Relation Diagram (ERD)}

Gambar 2 menerangkan tentang Entity Relation Diagram yang terdiri dari tabel-tabel, diantaranya tabel pelanggan, tabel transaksi, tabel detail transaksi, tabel pegawai, tabel retur, dan tabel barang yang merupakan bagian dari perancangan Database dalam sistem aplikasi 
program kasir pada toko Citra MJ. Berikut ini adalah database yang digunakan dalam perancangan program kasir di toko MJ. 1) Tabel Pegawai, tabel pegawai yang berisi data-data pegawai dari toko MJ, 2) Tabel Pelanggan, tabel pelanggan berisi data-data pelanggan yang berisi 5 field, 3) Tabel Transaksi, table transaksi menyimpan transaksi penjualan pada toko MJ, 4) Tabel Barang, tabel barang berisi data-data barang yang terdapat pada toko MJ, 5) Tabel Detail transaksi, tabel detail transaksi yang menyimpan data transaksi yang lebig detai dari penjualan pada toko MJ, 6) Tabel Retur, tabel retur merupakan tabel yang berfungsi untuk proses penjualan pelunasan pembayaran, 7) Tabel Detail Retur, tabel yang berisi retur penjualan yang lebih detail.

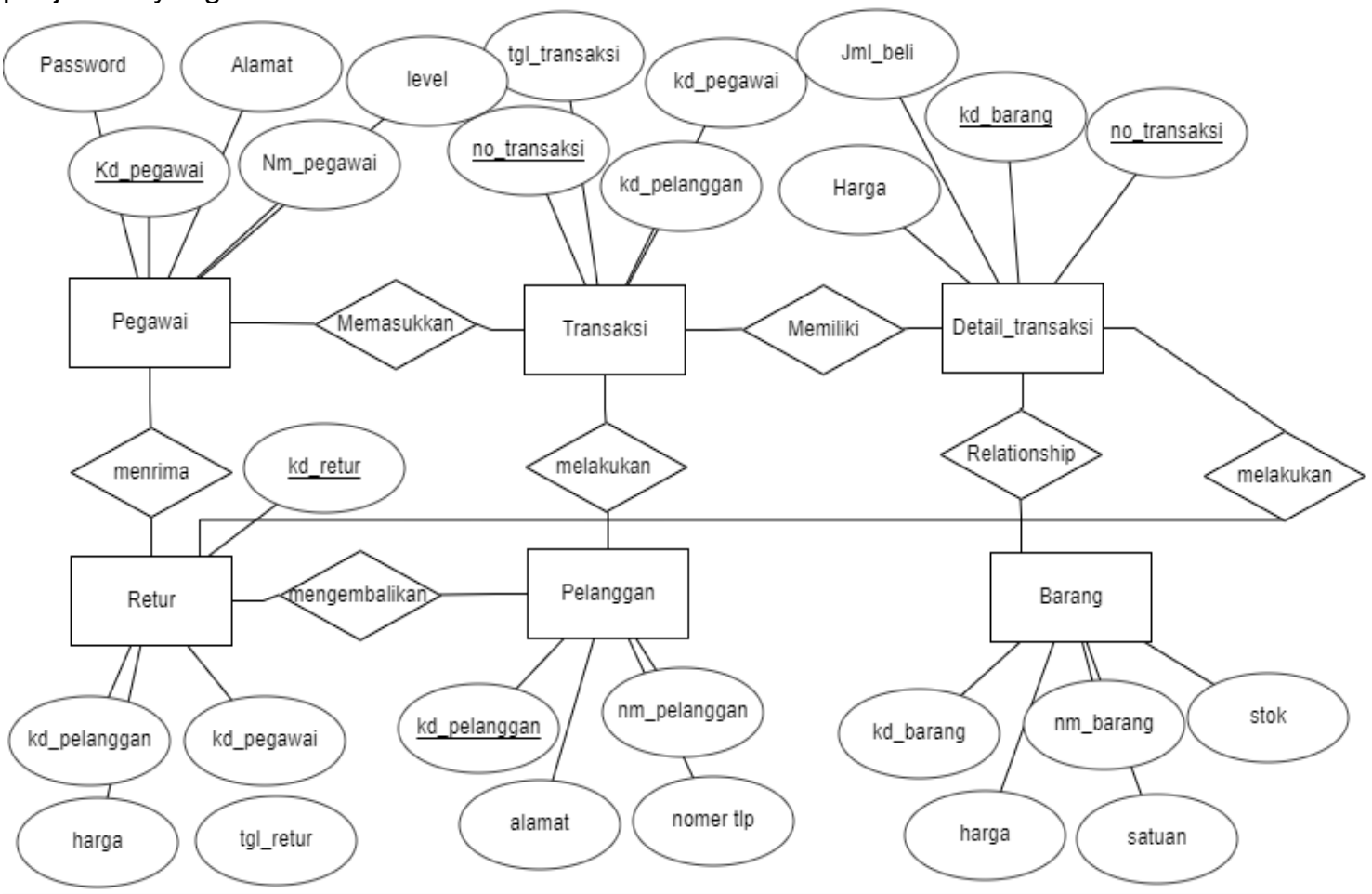

Sumber: Hasil Penelitian (2019)

Gambar 2. Entity Relation Diagram Program Kasir

\section{Pengkodean}

Dalam pengkodean ada yang disebut dengan struktur pengkodean, yang mana struktur kode tersebut merupakan kode yang dirangkai untuk dijadikan Primary Key pada sebuah tabel yang akan menjadi unik dan berbeda untuk setiap barisnya. Dalam hal ini struktur kode yang akan dibahas salah satunya adalah kode barang, dimana pada barang terdapat identitas untuk barang yang dituliskan pada tiga digit pertama, tanggai penginputan barang dituliskan setelah identitas barang dan nomor urut barang yang di tulislkan setelah tanggal penginputan yaitu 3 digit terakhir. Yang semuanya dituliskan dengan singkatan yang merupakan kode unik.

\section{Spesifikasi Program}

Disamping perancangan database peneliti juga membuat spesifikasi program dari program kasir pada toko $\mathrm{Mj}$, spesifikasi program kasir menjelaskan tentang proses yang ada di dalam program kasir tersebut. Dimulai dari HIPO yang menjelaskan tentang hubungan relasi penginputan, pemrosesan dan keluaran, dimana pada penginputan data menunjukkan itemitem data yang akan digunakan oleh bagian proses yang salah satunya berisi langkah-langkah kerja dari fungsi modul yang hasil akhirnya berupa output yang berisi hasil pemrosesan data. HIPO pada toko Citra MJ terdiri dari menu master, menu transaksi dan laporan, dimana menu master terdapat menu barang berisi, menu pegawai dan menu pelanggan, untuk transaksi terdiri dari menu penjualan dan retur, untuk menu laporan terdiri dari laporan penjualan, laporan retur dan laporan barang. Berikut ini spesifikasi program kasir dari toko MJ: 1) Form halaman 
login berfungsi sebagai keamanan, hanya yang terdaftar yang dapat menggunakan program tersebut disamping itu juga sebagai form awal untuk masuk ke menu dengan memasukkan id_pegawai dan password, 2) Form menu utama berfungsi untuk melihat menu pilihan yang ada di program diantaranya menu data pegawai untuk mengolah data pegawai, menu pelanggan utuk mengolah data pelanggan, menu barang untuk mengolah data barang, menu transaksi atau penjualan untuk mengolah data penualan, menu retur untuk pelunasan penjualan dan menu laporan untuk melihat laporan pegawai, pelanggan serta laporan penjualan, 3) Form pelanggan berfungsi untuk mengelola data pelanggan, dalam form ini terdapat beberapa field seperti kode pelanggan, nama pelanggan, telepon, alamat, jenis kelamin dan tanggal gabung, 4) Form barang berfungsi untuk mengelola data barang, dalam form ini terdapat inputan seperti kode barang, nama barang, ukuran barang stok barang dan lainnya, 5) Form penjualan berfungsi untuk proses penjualan, dalam form ini juga dapat melihat data barang, data pelanggan dan data penjualan serta dapat mencetak bukti penjualan, 6) Form retur berfungsi untuk proses pelunasan pembayaran pada penjualan, dalam form retur terdapat proses menghitung total bayar, mencetak dan menyimpan bukti penjualan.

\section{Implementasi Sistem}

Penerapan sistem dalam rancangan antar muka pada aplikasi program kasir di Toko Citra Mj diantaranya:

\section{Halaman Menu utama pemilik}

Gambar 3 menjelaskan tentang menu utama pemilik, dimana setelah pengguna berhasil memasukkan NIK dan password akan muncul menu utama dari aplikasi yang dapat dioperasikan oleh pemilik, semua menu yang terdapat di aplikasi dapat dioperasikan oleh pemilik.

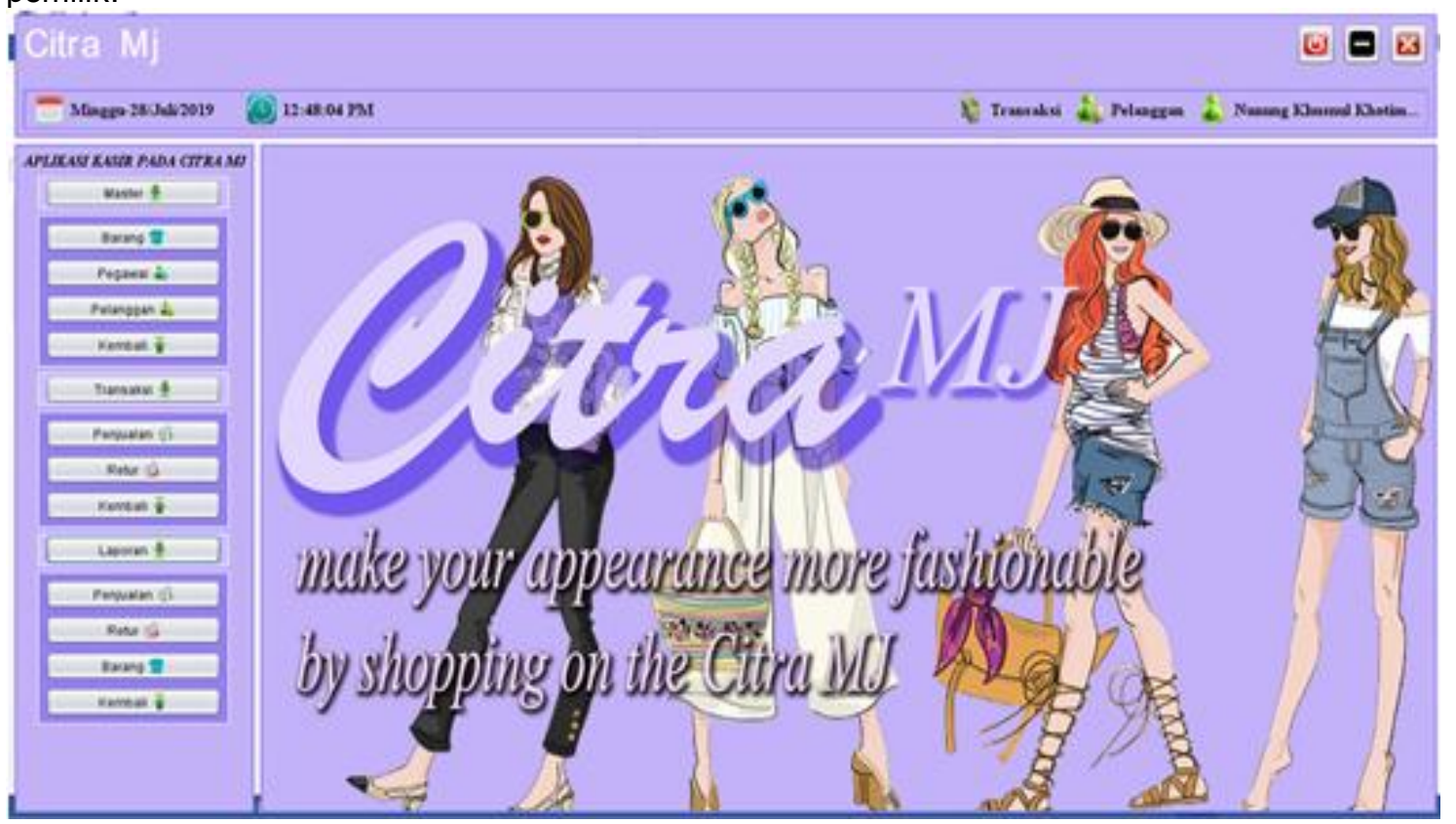

Sumber: Hasil penelitian (2019)

Gambar 3. Menu Utama Pemilik

\section{Halaman Menu Utama Kasir}

Berdasarkan gambar 4 yaitu: halaman menu utama kasir yang menjelaskan pada halaman menu kasir hanya terdapat beberapa form yang dapat di akses oleh kasir seperti misalnya input data kasir dan input transaksi yang terjadi, lain dengan pemilik yang dapat mengelola semua form pada aplikasi namun pada menu pegawai tidak bisa diinput karena hanya pemilik yang bisa input semua data menu di aplikasi. 


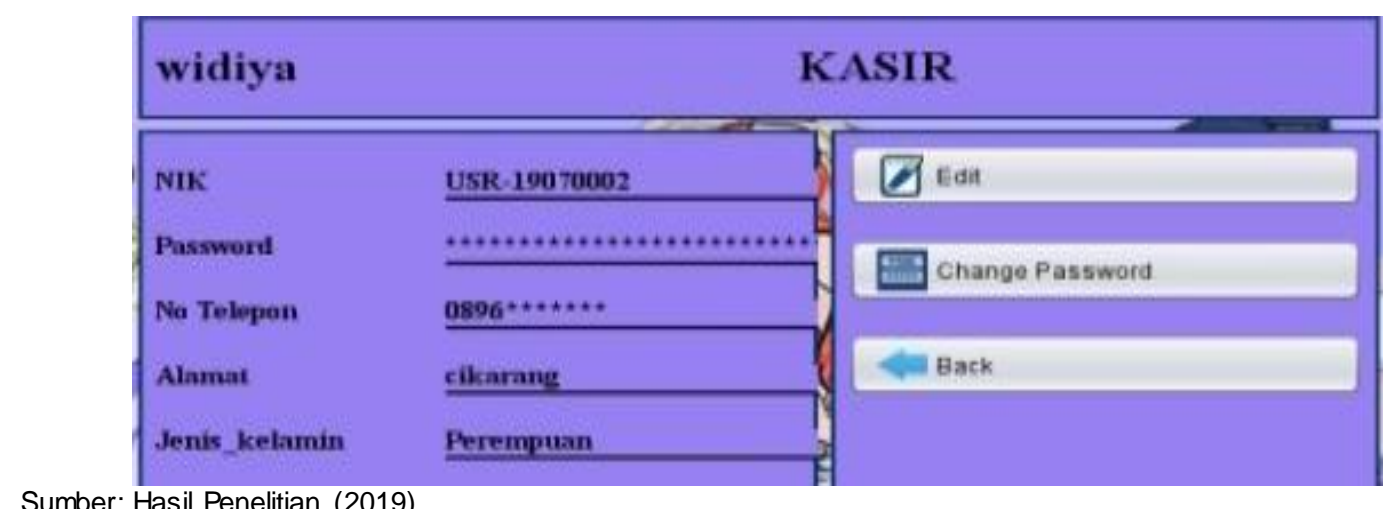

Sumber: Hasil Penelitian (2019)

Gambar 4. Halaman Menu Utama Kasir

\section{Halaman From Penjualan}

Berdasarkan gambar halaman 5 yaitu halaman form penjualan yang menjelaskan halaman pemilik, kasir dan pramuniaga bisa menggunakan transaksi penjualan. Dimana pada aplikasi ini terdapat data transaksi penjualan dan detail transaksi penjualan yang dapat di input oleh kasir, pemilik dan pramuniaga.

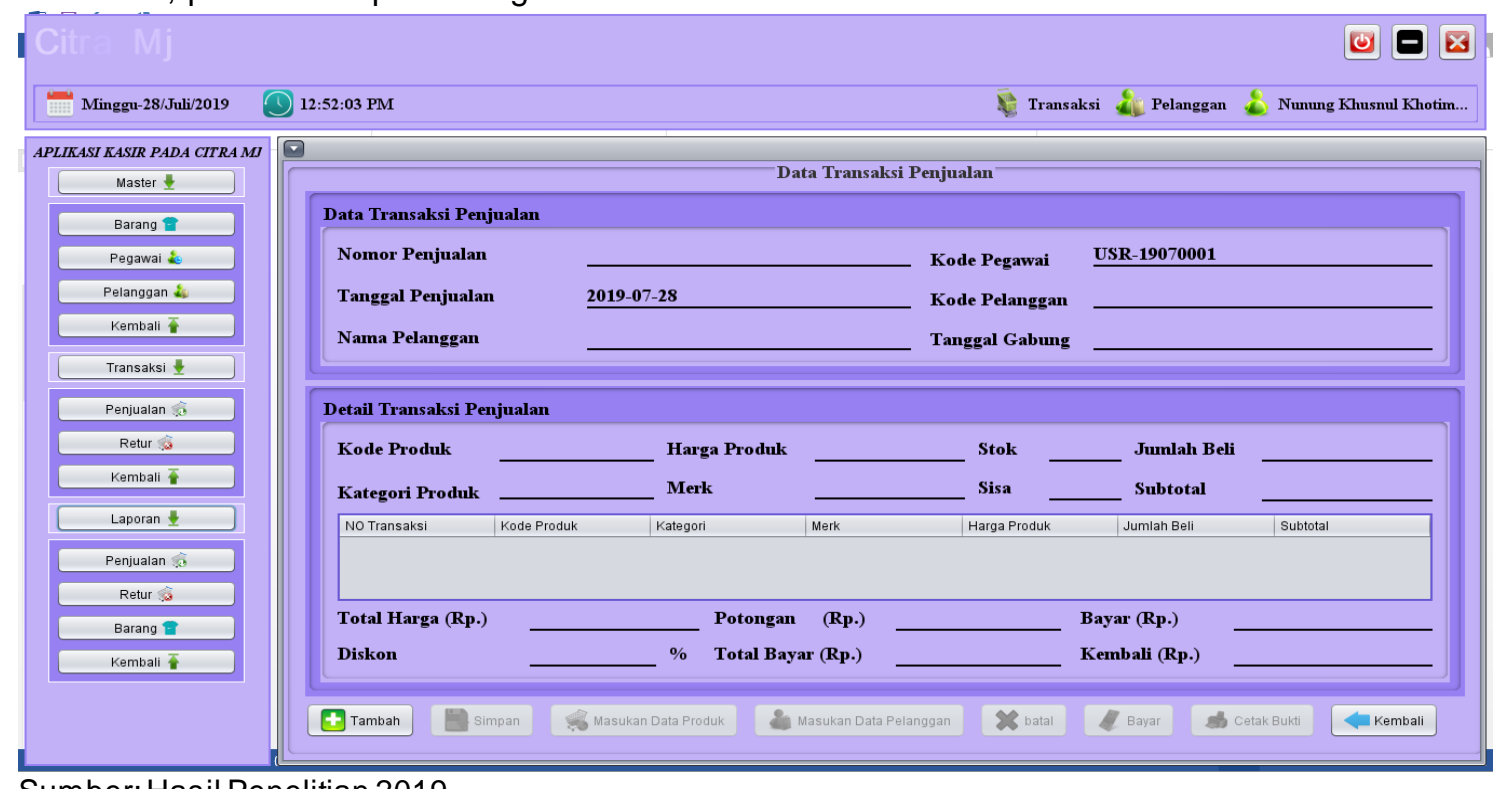

Sumber:Hasil Penelitian 2019

Gambar 5. Halaman Form Penjualan

\section{Pengujian Unit}

Pengujian black box testing merupakan salah satu dari pengujian unit, pengujian black box testing pada aplikasi program kasir difokuskan pada proses penginputan dan keluaran dari program kasir. Pengujian testing ini digunakan untuk mengetahui keterbatasan dari program. Diharapkan dengan adanya pengujian ini aplikasi dapat running sesuai yang diinginkan. Pada program kasir ini hanya dilakukan pengujian berdasarkan black box testing saja, yang mana pengujian black box testing dilakukan dengan membuat kasus uji yang bersifat mencoba semua fungsi dengan menggunakan software atau perangkat lunak apakah sesuai dengan spesifikasi yang dibutuhkan atau tidak. Dalam hal ini pengujian program kasir pada toko Citra MJ dilakukan pada beberapa kegiatan diantaranya yang akan ditampilkan adalah form login dan pelanggan saja.

\section{Pengujian pada form login}

Pada tabel 1 diatas menjelaskan tentang hasil pengujian black box testing pada halaman login, Pada tabel ini login menjelaskan tentang proses login mulai dari memasukan nama pengguna dan kata kunci sampai proses login masuk, dimana penginputan username 
atau NIK yang benar dan password yang salah atau sebaliknya yang kemudian di uji dengan hasil yang sesuai harapan dan hasil pengujian juga sesuai harapan maka dapat disimpulkan bahwa program kasir pada form login dengan pengujian username yang di ujikan valid. Proses tersebut dilakukan berulang dengan kasus berbeda sampai mendapatkan hasil yang diharapkan.

Tabel 1. Hasil Pengujian Black Box Testing pada Halaman Login

\begin{tabular}{|c|c|c|c|c|c|}
\hline No & Skenario Pengujian & Test Case & $\begin{array}{l}\text { Hasil yang } \\
\text { diharapkan }\end{array}$ & $\begin{array}{l}\text { Hasil } \\
\text { Pengujian }\end{array}$ & Kesimpulan \\
\hline 1 & $\begin{array}{l}\text { NIK dan password tidak } \\
\text { diisi kemudian klik tombol } \\
\text { konfirmasi }\end{array}$ & $\begin{array}{l}\text { NIK: (Kosong) } \\
\text { Passw ord: (Kosong) }\end{array}$ & $\begin{array}{l}\text { Sistem akan menolak } \\
\text { akses NIK dan } \\
\text { menampilkan "Kode } \\
\text { Akses Kosong” } \\
\end{array}$ & $\begin{array}{l}\text { Sesuai } \\
\text { Harapan }\end{array}$ & Valid \\
\hline 2 & $\begin{array}{l}\text { Mengetikan NIK dan } \\
\text { password tidak diisi atau } \\
\text { kosong kemudian klik } \\
\text { konfirmasi }\end{array}$ & $\begin{array}{l}\text { NIK:123 } \\
\text { Passw ord: (kosong) }\end{array}$ & $\begin{array}{l}\text { Sistem akan menolak } \\
\text { hak akses NIK dan } \\
\text { menampilkan "Kata } \\
\text { Sandi kosong" }\end{array}$ & $\begin{array}{l}\text { Sesuai } \\
\text { Harapan }\end{array}$ & Valid \\
\hline 3 & $\begin{array}{l}\text { NIK tidak diisi (kosong) } \\
\text { dan passworddiisi } \\
\text { kemudian klik tombol } \\
\text { konfirmasi }\end{array}$ & $\begin{array}{l}\text { NIK: (kosong) } \\
\text { password: Admin }\end{array}$ & $\begin{array}{l}\text { Sistem akan menolak } \\
\text { akses NIK dan } \\
\text { menampilkan "kata } \\
\text { sandi salah" }\end{array}$ & $\begin{array}{l}\text { Sesuai } \\
\text { Harapan }\end{array}$ & Valid \\
\hline 4 & $\begin{array}{l}\text { Mengetikan salah satu } \\
\text { kondisi salah pada NIK } \\
\text { atau password kemudian } \\
\text { klik tombol login } \\
\end{array}$ & $\begin{array}{l}\text { NIK: usr-19070001 } \\
\text { (benar) } \\
\text { Passw ord: } 1234 \text { (salah) }\end{array}$ & $\begin{array}{l}\text { Sistem akan menolak } \\
\text { akses NIK dan } \\
\text { menampilkan "kata } \\
\text { sandi salah" }\end{array}$ & $\begin{array}{l}\text { Sesuai } \\
\text { Harapan }\end{array}$ & Valid \\
\hline 5 & $\begin{array}{l}\text { Mengetikan NIK dan } \\
\text { password yang benar } \\
\text { kemudian klik tombol login }\end{array}$ & $\begin{array}{l}\text { NIK: usr-19070001 } \\
\text { (benar) } \\
\text { Passw ord: } 12345 \\
\text { (benar) }\end{array}$ & $\begin{array}{l}\text { Sistem akan menerima } \\
\text { akses login dan } \\
\text { kemudian langsung } \\
\text { menampilkan menu } \\
\text { utama }\end{array}$ & $\begin{array}{l}\text { Sesuai } \\
\text { Harapan }\end{array}$ & Valid \\
\hline
\end{tabular}

Sumber: Hasil Penelitian (2019)

\section{Pengujian Pada Form Pelanggan}

Pada Tabel 2 menjelaskan tentang pengujian pada form pelanggan, dimana id pelanggan muncul otomatis sedangkan semua data di kosongkan, kasus kedua membuat satu atau dua data kosong dan kasus tiga mengisi semua data dengan hasil pengujian sesuai harapan untuk semua kasus, yang nantinya hasil pengujian dari beberapa kasus tersebut adalah sesuai harapan, jadi program kasir pada toko Citra MJ untuk form pelanggan dapat disimpulkan bahwa pengujian program kasir yang diujikan valid.

Tabel 2. Hasil Pengujian Black Box Testing pada Halaman Pelanggan

\begin{tabular}{|c|c|c|c|c|c|}
\hline No & Skenario Pengujian & Test Case & $\begin{array}{l}\text { Hasil yang } \\
\text { diharapkan }\end{array}$ & $\begin{array}{l}\text { Hasil } \\
\text { Pengujian }\end{array}$ & Kesimpulan \\
\hline 1 & $\begin{array}{l}\text { Id Pelanggan muncul } \\
\text { otomatis jika mengklik } \\
\text { button tambah, } \\
\text { Semua data } \\
\text { dikosongkan }\end{array}$ & $\begin{array}{l}\text { Id Pelanggan: (otomatis) } \\
\text { Nama pelanggan: (kosong) } \\
\text { Telepon (kosong) } \\
\text { Jenis kelamin (kosong) } \\
\text { Tanggal gabung (kosong) } \\
\text { Alamat (kosong) }\end{array}$ & $\begin{array}{l}\text { Sistem akan } \\
\text { menolak dan } \\
\text { menampilkan } \\
\text { "lengkapi } \\
\text { data" }\end{array}$ & $\begin{array}{l}\text { Sesuai } \\
\text { Harapan }\end{array}$ & Valid \\
\hline 2 & $\begin{array}{l}\text { Membuat satu atau } \\
\text { dua data kosong }\end{array}$ & $\begin{array}{l}\text { Id Pelanggan: (otomatis) } \\
\text { Nama pelanggan: baekhyun } \\
\text { Telepon 0897543345112 } \\
\text { Jenis kelamin Laki-Laki } \\
\text { Taanggal gabung } 14 \text { Juli } 2019 \\
\text { Alamat }\end{array}$ & $\begin{array}{l}\text { Sistem akan } \\
\text { menolak dan } \\
\text { menampilkan } \\
\text { "lengkapi } \\
\text { data" }\end{array}$ & $\begin{array}{l}\text { Sesuai } \\
\text { Harapan }\end{array}$ & Valid \\
\hline 3 & Mengisi semua data & $\begin{array}{l}\text { Id Pelanggan: } \\
\text { Nama pelanggan: baekhyun } \\
\text { Telepon } 0897543345112 \\
\text { Jenis kelamin Pria } \\
\text { Tanggal gabung } 14 \text { Juli } 2019 \\
\text { Alamat seoul }\end{array}$ & $\begin{array}{l}\text { Sistem akan } \\
\text { menerima dan } \\
\text { menampilkan } \\
\text { "Data telah } \\
\text { simpan" }\end{array}$ & $\begin{array}{l}\text { Sesuai } \\
\text { Harapan }\end{array}$ & Valid \\
\hline
\end{tabular}

Sumber: Hasil Penelitian (2019)

\section{Hasil Pengujian Tingkat Kepuasan pelanggan}

Hasil pengujian tingkat kepuasan pelanggan dijelaskan pada tabel 3.

Tabel 3. Daftar Pertanyaan Kuesioner

\begin{tabular}{ll}
\hline No & Kriteria \\
\hline 1 & Apakah menurut Anda aplikasi programkasir ini sangat mudah untuk digunakan? \\
\hline 2 & Apakah menurut Anda aplikasi programkasir ini sudah memenuhi kebutuhan Anda? \\
\hline
\end{tabular}




\begin{tabular}{ll}
\hline No & Kriteria \\
\hline 3 & Apakah anda setuju bahw a aplikasi program kasir ini bermanfaat dan memudahkan pekerjaan Anda? \\
\hline 4 & Apakah Anda setuju dengan aplikasi programini dapat mempercepat pekerjaan Anda? \\
\hline 5 & Apakah Anda setuju dengan aplikasi programini menu laporan sesuai dengan yang dibutuhkan? \\
\hline 6 & Apakah Anda setuju aplikasi program ini lebih memudahkan Anda dalam penginputan data? \\
\hline 7 & Apakah anda setuju bahw a programini dapat bermanf aat bagi pegaw ai dan konsumen \\
\hline 8 & Apakah Anda setuju aplikasi program ini memiliki kekurangan yang mendasar? \\
\hline 9 & Apakah Anda setuju aplikasi program ini sudah terupdate terbaru \\
\hline 10 & Apakah Anda setuju ada aplikasi yang lebih baik dari aplikasi ini? \\
\hline
\end{tabular}
Sumber: Hasil Penelitian (2019)

Indikator penilaian dijelaskan pada tabel 4.

Tabel 4. Indikator Penilaian

\begin{tabular}{ll}
\hline \multicolumn{1}{c}{ Indikator } & Nilai \\
\hline Sangat Setuju & 5 \\
\hline Setuju & 4 \\
\hline Cukup & 3 \\
\hline Kurang Setuju & 2 \\
\hline Tidak setuju & 1 \\
\hline Sumber: Hasil Penelitian (2019)
\end{tabular}

Sumber: Hasil Penelitian (2019)

Total nilai maksimal untuk indicator penilaian $=50$

Presentase Kepuasan pengguna (\%) = Total Nilai Pengguna $\times 100 \%$

Total Nilai Maksimal

$$
=\frac{349}{425} \times 100 \%
$$$$
=82,12 \%
$$

Dilihat dari hasil persentase pengukuran tingkat kepuasan pengguna yaitu $82,12 \%$ yang telah dilakukan terhadap 15 responden maka dapat disimpulkan bahwa pengguna sangat puas terhadap rancangan aplikasi program kasir pada toko Citra MJ.

\section{Kesimpulan}

Perancangan aplikasi program kasir pada toko Citra MJ sangat di butuhkan dikarenakan pengolahan data terdahulu masih menggunakan sistem manual dengan cara dicatat dalam lembaran kertas dan pencatatannya pun kurang jelas. Sehingga pada saat ini sangat dibutuhkan sekali aplikasi program yang dapat membantu kasir pada toko Citra MJ. Rancangan program kasir ini telah dilakukan pengujian dengan menggunakan black box testing yang hasilnya semua fungsi dapat berfungsi dengan baik. Untuk antisipasi terhadap kerusakan dari aplikasi program maupun perangkat keras, sebaiknya dalam jangka waktu tertentu dilakukan backup data dari database yang dibuat ke dalam penyimpanan luar. Selain itu juga dilihat dari hasil kepuasan pengguna yang dilihat dari hasil kuisioner dari 15 responden menyatakan bahawa pengguna sangat puas dengah adanya aplikasi program kasir pada toko MJ yang dapat membantu kerja mereka. Pengembangan program ini nanti nya bisa dibuatkan webnya agar lebih luas cakupannya dan menambah pendapatan pada toko MJ.

\section{Referensi}

[1] S. A. Fauzi \& W. Wulandari, "Sistem Informasi Penjualan Produk Berbasis Web Pada Chanel Distro Pringsewu," J. Technologi Acceptance Model (TAM), vol.4, 2017.

[2] Yurindra, Software Engineering. Yogyakarta: Deepublish, 2017.

[3] Y. Dewi, W. Diah, Kurniawan \& Komalasari, "Sistem Informasi Penerimaan Siswa Baru Dengan Model Waterfall Pada Yayasan As-Sabiquun," Jurnal Bina Insani ICT, vol. 7, 2020.

[4] P. Febrianto, A., \& Handayani. "Rancang Bangun Sistem Pelayanan Jasa Bubut Berbasis Web Pada CV. Sukses Abadi Jaya Tanggerang", J. Paradigma, vol. 21, 2019, doi: https://doi.org/10.31294/p.v20i2.

[5] T. Julia, K. Kawengian, E. Mingkid \& Pantow, "Peranan Komunikasi Pemerintah Dalam Pelaksanakan Program Bersih Kampung," J. Umuslim, vol. 6, 2017.

[6] A. Kadir. Dasar Logika Pemrograman Komputer. Jakarta: Elex Media Komputindo, 2017.

[7] H. S. Haqi, Setiawan B., Aplikasi Absensi Dosen Dengan Java Dan Smartphone Sebagai Barcode Reader. Jakarta: Elexmedia Komputindo, 2019.

[8] U. Rusmawan, Teknik Penulisan Tugas Akhir Dan Skripsi Pemrograman. Jakarta: 
BINA INSANI ICT JOURNAL ISSN: 2355-3421 (Print) ISSN: 2527-9777 (Online); 136 - 145

Elexmedia Komputindo, 2019.

[9] A. Masturoh, Siti, Wijayanti, Diah, Prasetyo, "Sistem Informasi Akademik Berbasis Web Menggunakan Metode Waterfall Pada SMK ITENAS Karawang," Jurnal Informatika, vol. 6, no.1, pp. 62-68, 2019.

[10] T. Fridayanthie, E. W., \& Mahdiati, "Rancang bangun Sisitem Informasi Permintaan ATK Berbasis Internet," Jurnal Khatulistiwa Informatika, vol. 4, no.2, pp.126-138, 2016.

[11] S. Pradiatiningtyas, D. E-Learning Sebagai Media Pembelajaran Berbasis Web Pada SMK N 4 Purworejo, Indones. Networking and Security (IJNS), vol. 7, no. 2, pp. 1-8, 2018.

[12] S. Sarosa, Metodologi Pengembangan Sistem Informasi. Jakarta: Indeks, 2017.

[13] Z. Wijayanti, Diah, Adha, Ridwan, Haryadi, Eko, "Sistem Absensi Real time Berbasis Web Madrasah Aliyah Wasilatul Falah Banten," Jurnal Bina Insani ICT, vol.7, pp. 11-20, 2020. 